\title{
IGFBP-1 expression is reduced in human type 2 diabetic glomeruli and modulates $\beta 1$-integrin/FAK signalling in human podocytes
}

\author{
Abigail C. Lay ${ }^{1}$ (D) Lorna J. Hale $^{1} \cdot$ Holly Stowell-Connolly ${ }^{1} \cdot$ Robert J. P. Pope ${ }^{1,2} \cdot$ Viji Nair $^{3,4} \cdot$ Wenjun Ju $^{3,4}$. \\ Eva Marquez ${ }^{1} \cdot$ Ruth Rollason $^{1} \cdot$ Jenny A. Hurcombe ${ }^{1}$ (I) $\cdot$ Bryony Hayes $^{1} \cdot$ Timothy Roberts $^{1} \cdot$ Lawrence Gillam $^{1}$. \\ Jonathan Allington ${ }^{1} \cdot$ Robert G. Nelson ${ }^{5}$ - Matthias Kretzler ${ }^{3,4}$ - Jeff M. P. Holly ${ }^{6}$. Claire M. Perks ${ }^{6}$. \\ Craig A. McArdle ${ }^{2}$ (D) - Gavin I. Welsh ${ }^{1} \cdot$ Richard J. M. Coward ${ }^{1}$ (I)
}

Received: 14 May 2020 / Accepted: 14 January 2021 / Published online: 24 March 2021

(C) The Author(s) 2021

\begin{abstract}
Aims/hypothesis Podocyte loss or injury is one of the earliest features observed in the pathogenesis of diabetic kidney disease (DKD), which is the leading cause of end-stage renal failure worldwide. Dysfunction in the IGF axis, including in IGF binding proteins (IGFBPs), is associated with DKD, particularly in the early stages of disease progression. The aim of this study was to investigate the potential roles of IGFBPs in the development of type $2 \mathrm{DKD}$, focusing on podocytes.

Methods IGFBP expression was analysed in the Pima DKD cohort, alongside data from the Nephroseq database, and in ex vivo human glomeruli. Conditionally immortalised human podocytes and glomerular endothelial cells were studied in vitro, where IGFBP-1 expression was analysed using quantitative PCR and ELISAs. Cell responses to IGFBPs were investigated using migration, cell survival and adhesion assays; electrical cell-substrate impedance sensing; western blotting; and high-content automated imaging.

Results Data from the Pima DKD cohort and from the Nephroseq database demonstrated a significant reduction in glomerular IGFBP-1 in the early stages of human type 2 DKD. In the glomerulus, IGFBP-1 was predominantly expressed in podocytes and controlled by phosphoinositide 3-kinase (PI3K)-forkhead box O1 (FoxO1) activity. In vitro, IGFBP-1 signalled to podocytes via $\beta 1$-integrins, resulting in increased phosphorylation of focal-adhesion kinase (FAK), increasing podocyte motility, adhesion, electrical resistance across the adhesive cell layer and cell viability.

Conclusions/interpretation This work identifies a novel role for IGFBP-1 in the regulation of podocyte function and that the glomerular expression of IGFBP-1 is reduced in the early stages of type $2 \mathrm{DKD}$, via reduced FoxO1 activity. Thus, we hypothesise that strategies to maintain glomerular IGFBP-1 levels may be beneficial in maintaining podocyte function early in DKD.
\end{abstract}

Keywords Adhesion · Diabetic nephropathy $\cdot$ FAK $\cdot$ Fkhr $\cdot$ FoxO1 $\cdot$ Glomerulus $\cdot$ IGFBP-1 $\cdot \beta 1$-integrin $\cdot$ Motility $\cdot$ Podocyte

Abbreviations

DKD Diabetic kidney disease

ECIS Electrical cell-substrate impedance sensing

EBM-2 Endothelial cell growth basal medium-2
ECM Extracellular matrix

FA Focal adhesion

FAK Focal-adhesion kinase

FoxO1 Forkhead box O1
Richard J. M. Coward

Richard.Coward@bristol.ac.uk

1 Bristol Renal, Bristol Medical School, University of Bristol, Bristol, UK

2 Translational Health Sciences, Bristol Medical School, University of Bristol, Bristol, UK

3 Division of Nephrology, Department of Internal Medicine, University of Michigan, Ann Arbor, MI, USA
4 Department of Computational Medicine and Bioinformatics, University of Michigan, Ann Arbor, MI, USA

5 National Institute of Diabetes and Digestive and Kidney Diseases, National Institutes of Health, Phoenix, AZ, USA

6 IGFs and Metabolic Endocrinology Group, Bristol Medical School, University of Bristol, Bristol, UK 


\section{Research in context}

\section{What is already known about this subject?}

- Podocyte dysfunction is a key event occurring early in the pathogenesis of diabetic kidney disease (DKD), the leading cause of end-stage kidney failure worldwide

- Dysfunction in the IGF axis, including in the IGF binding proteins (IGFBPs), is associated with DKD development

- IGFBPs are modulated early in the progression of type 2 diabetes and can have IGF-independent effects on cell function

\section{What is the key question?}

- Do local glomerular levels of IGFBPs change in DKD and can IGFBPs influence podocyte function?

What are the new findings?

- Glomerular /GFBP-1 expression is reduced early in type $2 \mathrm{DKD}$, where it is predominantly expressed in podocytes

- Podocyte IGFBP-1 expression is controlled by FoxO1, which is inhibited by active insulin-PI3K-Akt signalling

- $\quad$ IGFBP-1 can enhance $\beta 1$-integrin activation and downstream FAK phosphorylation in human podocytes, alongside increasing cell adhesion, motility and survival—responses that are essential for podocyte function

\section{How might this impact on clinical practice in the foreseeable future?}

- These results show that IGFBP-1 could have beneficial effects on podocyte function and that a loss of glomerular IGFBP-1 occurs early in type 2 DKD. As such, strategies to maintain glomerular IGFBP-1 levels may be therapeutically beneficial in early diabetic nephropathy

\begin{tabular}{|c|c|}
\hline GBM & Glomerular basement membrane \\
\hline IGFBP & IGF binding protein \\
\hline IGF-IR & IGF-I receptor \\
\hline MTS & $\begin{array}{l}\text { 3-(4,5-Dimethylthiazol-2-yl)-5- } \\
\text { (3-carboxymethoxyphenyl)-2- } \\
\text { (4-sulfophenyl)-2H-tetrazolium }\end{array}$ \\
\hline JIDDK & $\begin{array}{l}\text { National Institute of Diabetes and } \\
\text { Digestive and Kidney Diseases }\end{array}$ \\
\hline & Phosphoinositide 3-kinase \\
\hline & Tris-NaCl-ethylenediaminetetraacet \\
\hline
\end{tabular}

\section{Introduction}

Diabetic kidney disease (DKD) occurs in approximately onethird of diabetic individuals and is the leading cause of endstage renal failure worldwide. Albuminuria often presents early during the development of DKD and is an important risk factor for the progression to both end-stage renal failure and cardiovascular disease [1].

Podocytes are highly specialised, terminally differentiated epithelial cells which line the urinary side of the glomerular basement membrane (GBM) in the kidney. These cells have essential roles in filtration barrier maintenance and, as such, podocyte loss or injury is a major cause of albuminuria in numerous settings, including DKD. Both the effacement of podocyte foot processes and reduction in podocyte number or density (as a result of cell detachment and apoptosis) occur early in the pathogenesis of DKD, as well as predicting the progression of DKD $[2,3]$. Thus, further understanding of the mechanisms involved in podocyte dysfunction in the setting of DKD is desirable.

The mammalian IGF axis comprises IGF-I and -II; their respective receptors, the IGF-I receptor (IGF-IR) and IGF-II/mannose-6-phosphate receptor (IGF-IIR/ M6PR); and a family of six IGF binding proteins (IGFBP-1-6). Dysregulation of IGF signalling is associated with several metabolic conditions including the development and progression of DKD, particularly in the early stages of disease [4]. IGFBPs have also been linked to the pathogenesis of albuminuric renal disease [5-7].

Although the primary functions of the IGFBPs were once thought to be binding IGF-I and -II within the circulation, prolonging their half-life as well as regulating their passage into tissues, it is now well recognised that IGFBPs can bind to the cell surface, exerting cell-specific, IGF-independent effects on cell growth, differentiation and survival [8-10].

While it is known that both IGF-I and IGF-II signalling can directly influence podocyte biology $[11,12]$, the roles of IGFBPs in this context are not well understood. However, there is evidence that podocytes can also respond to IGFBP stimulation $[5,6]$. The effects of IGFBPs in podocytes in the context of DKD have not been reported. In this study, we explored the local, glomerular production of IGFBPs in 
DKD and the IGF-independent effects of IGFBPs on podocytes.

\section{Methods}

Human samples IGFBP expression was analysed in precollected gene expression data from the Pima DKD cohort, alongside existing expression data in the Nephroseq database. Background information from the Pima DKD study is as follows: Protocol human kidney biopsies were obtained from Pima Indians $(n=69)$ with type 2 diabetes from the Gila River Indian Community. The study participants were enrolled in a randomised, double-blinded, placebo-controlled interventional clinical trial funded by the National Institute of Diabetes and Digestive and Kidney Diseases (NIDDK) [13]. The study was approved by the Institutional Review Board of the NIDDK and each participant signed an informed consent document. Kidney tissue processing and microarray preparation were described previously [14]. Gene expression profiling and pre-processing were done using GeneChip Human Genome series U133A and Plus 2.0 Array (Affymetrix, Santa Clara, CA, USA) $[15,16]$. Further details are listed in the Electronic supplementary material (ESM) Methods.

Nephroseq Data from the Nephroseq (www.nephroseq.org, University of Michigan, Ann Arbor, MI, USA) and Nephrocell (http://nephrocell.miktmc.org/) databases were extracted to further examine gene expression in human kidney. IGFBP expression data were obtained from the datasets: 'Woroniecka Diabetes Glom' [17]; 'Lindenmeyer Normal Tissue Panel' [18].

Ex vivo human glomeruli For ex vivo glomerular studies, glomeruli were isolated from human kidneys that were unsuitable for transplantation. Perfused kidneys were placed on ice and glomeruli were isolated by passing sequentially through sieves with pore sizes $425 \mu \mathrm{m}, 180 \mu \mathrm{m}, 125 \mu \mathrm{m}$ and $90 \mu \mathrm{m}$, as described previously [19]. All studies on human kidney tissue were approved by national and local research ethics committees (Institutional Ethical Committee, South WestCentral Bristol National Health Service Research Ethics Committee, UK; and East Midlands-Leicester National Health Service Research Ethics Committee, UK), and conducted in accordance with the tenets of the Declaration of Helsinki.

Cell culture and stimulations Conditionally immortalised human podocytes [19] were grown to $80 \%$ confluence in RPMI-1640 containing L-glutamine and $\mathrm{NaHCO}_{3}$, and supplemented with $10 \%$ FBS (Sigma Aldrich, UK), at $33^{\circ} \mathrm{C}$ with $5 \% \mathrm{CO}_{2}$ before thermo-switching to $37^{\circ} \mathrm{C}$ in $5 \% \mathrm{CO}_{2}$, and allowed to differentiate for 9-12 days. Conditionally immortalised glomerular endothelial cells [20] were maintained in Endothelial Cell Growth Basal Medium-2 (EBM2), containing microvascular SingleQuots Supplement Pack in 5\% FBS (Lonza, UK). All cells were free of mycoplasma contamination. Human podocytes expressing forkhead box O1 (FoxO1)-clover were generated as previously described [21], using pLenti-FoxO1-clover (a gift from P. Rotwein, Addgene plasmid no. 67759; http://n2t/addgene:67759; RRID:Addgene_67759).

Differentiated cells were incubated with serum-, insulinand IGF-free RPMI-1640, or EBM-2, for 2-6 h, before indicated stimulation. The FoxO1 inhibitor, AS1842856 (Merck, Watford, UK), was used at $50 \mathrm{ng} / \mathrm{ml}$ for the stated times. Insulin (100 nmol/l, unless otherwise stated), Wortmannin (phosphoinositide 3-kinase [PI3K] inhibitor, $200 \mathrm{nmol} / \mathrm{l}$ ) and GSK694002 (Akt inhibitor, $200 \mathrm{nmol} / \mathrm{l}$ ) were purchased from R\&D Systems (Abingdon, UK). Human recombinant IGFBP1-6 were obtained from Gropep Bioreagents (Australia) and R\&D Systems. Doses of IGFBPs were taken from previous publications $[9,22,23]$. Pre-treatment with the anti- $\beta 1$ integrin antibody, P5D2 (Merck), was at $100 \mathrm{ng} / \mathrm{ml}$ or $1000 \mathrm{ng} / \mathrm{ml}$ for $30 \mathrm{~min}$.

Quantitative RT-PCR Total RNA was isolated using an RNeasy Mini Kit (QIAGEN, Germany), and cDNA was synthesised using a high-capacity RNA-cDNA kit (ThermoFisher Scientific, UK). Quantitative RT-PCR was performed using SYBR green (Sigma Aldrich) in a StepOnePlus system (ThermoFisher Scientific) for human IGFBP-1 (forward: TTTTACCTGCCAAACTGCAACA, reverse: CCCATTCCAAGGGTAGACGC) normalised to $B$-ACTIN (forward: GACAGGATGCAGAAGGAGAT TACT, reverse: TGATCCACATCTGCTGGAAGGT).

IGFBP-1 ELISA Cellular and secreted IGFBP-1 levels were quantified using an IGFBP-1 ELISA (R\&D Systems), as per the manufacturer's instructions. For quantification of secreted IGFBP-1 levels, cell-free medium was collected after a 6 or $24 \mathrm{~h}$ incubation with cells or glomeruli, $100 \mu \mathrm{l}$ was added to the ELISA and IGFBP-1 levels were normalised to total protein concentration, quantified using bicinchoninic acid (BCA) (ThermoFisher Scientific) and Bradford assays (Abcam, Cambridge, UK).

Western blotting Total protein lysates were extracted using RIPA lysis buffer (Sigma Aldrich), resolved using SDSPAGE and blotted onto PVDF membranes. Membranes were incubated in primary antibodies overnight at $4{ }^{\circ} \mathrm{C}$, before washing and incubation with the appropriate horseradish peroxidase (HRP)-conjugated secondary antibody (Sigma Aldrich) at 1:10,000 dilution. Immunoreactive bands were visualised using Clarity ECL Western Blotting Substrate (Bio-Rad, Hemel Hempstead, UK) on a AI600 imager (GE 
Healthcare, Amersham, UK) and quantified using ImageJ (NIH, https://imagej.nih.gov/ij/). Primary antibodies are listed in the ESM Methods.

Active $\beta 1$-integrin immunoprecipitation Proteins were extracted in Tris-NaCl-ethylenediaminetetraacetic acid (TNE) (100 mM Tris- $\mathrm{HCl}$ [pH 7.4], 150 mM NaCl, $0.1 \mathrm{mM}$ EDTA) containing 2\% NP40 and protease inhibitors (Sigma Aldrich). Clarified lysates were incubated with $1 \mu \mathrm{g}$ of active $\beta 1$-integrin (Merck) or isotype-matched IgG control, overnight at $4{ }^{\circ} \mathrm{C}$, under constant rotation, before incubation with $15 \mu \mathrm{l}$ of protein-A/G Sepharose for $3 \mathrm{~h}$ at $4^{\circ} \mathrm{C}$, under rotation. Immune complexes were pelleted at $1000 \mathrm{~g}$ and washed in chilled TNE. Lysates were resolved on 10\% SDS-PAGE gels and probed with a total- $\beta 1$-integrin antibody (NEB, Hertfordshire, UK).

Cell motility assay Cell motility was measured using a modified wound healing assay to model cytoskeletal regulation, as previously described [24]. Cells were grown to confluence in CELLSTAR tissue-culture (TC)-treated six-well culture plates with no additional protein coating; starved of serum, insulin and IGF; and wounded with a sterile $0.2 \mathrm{~mm}$ tip. Images were acquired at 0 and $14 \mathrm{~h}$, following stimulation with IGFBPs, and the distance of migration was measured in ImageJ.

InnoCyte cell adhesion assay InnoCyte extracellular matrix (ECM) cell adhesion assays (Merck) were performed according to the manufacturer's instructions. Briefly, differentiated podocytes were resuspended in serum-free RPMI at densities between 100,000 and 500,000 cells $/ \mathrm{ml}$. Then, $100 \mu \mathrm{l}$ of the cell suspension was added to wells of the ECM protein-coated plate and incubated for $2 \mathrm{~h}$ at $37^{\circ} \mathrm{C}$. The cell suspension was then discarded, and the plate washed with PBS before the addition of a calcein-AM solution and further incubation at $37^{\circ} \mathrm{C}$ for $1 \mathrm{~h}$. The fluorescence in each well was measured at an excitation wavelength of $\sim 485 \mathrm{~nm}$ and an emission wavelength of $\sim 520 \mathrm{~nm}$.

Puromycin cell survival studies The Promega CellTiter 96 AQueous One Solution Cell Proliferation Assay (3-(4,5dimethylthiazol-2-yl)-5-(3-carboxymethoxyphenyl)-2-(4sulfophenyl)-2H-tetrazolium; MTS assay) was utilised to examine the number of living cells after treatment. Puromycin dihydrochloride (Sigma Aldrich) was used at $50 \mu \mathrm{g} / \mathrm{ml}$ for $18 \mathrm{~h}$ to induce cell death.

Electrical Cell-substrate Impedance Sensing Resistance measurement was performed using an automated cell monitoring system, electrical cell-substrate impedance sensing (ECIS) (ECIS 1600R, Applied Biophysics, NY, USA), as previously described [25]. Briefly, human podocytes were seeded onto gold microelectrode ECIS arrays (Applied Biophysics) at a density of $1 \times 10^{6}$ cells $/ \mathrm{cm}^{2}$. Following differentiation, podocytes were serum-starved for $4 \mathrm{~h}$ and stimulated with IGFBP-1-6 or vehicle. Resistance was measured (ohms) at regular intervals for $24 \mathrm{~h}$ and presented as a ratio to vehicle-treated cells.

Semi-automated immunofluorescent imaging and analysis Podocytes were grown in 96-well plates (Greiner, Stonehouse, UK), stimulated as indicated before fixation and immunostaining. Image acquisition was automated using an IN Cell Analyzer 2200 (GE Healthcare) imaging platform, with $\mathrm{a} \times 10$ or $\times 20$ objective, and quantified using IN Cell Analyzer work station 3.5 software, as previously described $[26,27]$. At least three technical replicates were performed within each experiment, with four fields of view per well, yielding data for $>600$ cells per condition, per experiment. For FoxO1-translocation assays, individual cell measurements were used to calculate the percentage of podocytes positive for nuclear FoxO1, where a positive cell had a ratio of nuclear to cytoplasmic (N:C) FoxO1 fluorescence greater than 1. For quantification of phosphorylated FAK and Paxillin, measurements of fluorescence intensity at focal adhesions were used. Phalloidin staining was used to visualise F-actin, the quantification of which was automated using IN Cell Developer software. Additional details can be found in the ESM Methods.

Statistics Data are presented as mean \pm SEM unless otherwise stated, with further details of statistical analysis provided in relevant figure legends. Analysis was performed using GraphPad Prism v8 (GraphPad Software, CA, USA), where statistical significance was calculated with one-way ANOVA with Tukey's multiple comparison test or $t$ tests. For Nephroseq data, statistical significance is presented as $p$ values computed using Welch's $t$ test and $q$ values (exported from Nephroseq) corrected using the Benjamini-Hochberg method. For gene expression analysis in the Pima diabetic cohort, differential expression was estimated using R (https://www.rproject.org/) with the limma package [28, 29], comparing control participants and early DKD, and adjusting for age and sex. The $p$ values were adjusted using the BenjaminiHochberg correction.

\section{Results}

Glomerular IGFBP-1 expression is reduced in human type 2 DKD To determine whether any differences in local glomerular expression of IGFBPs occurred in DKD, we initially analysed existing data from the renal transcriptomics database Nephroseq. In the 'Woroniecka Diabetes Glom' dataset [17], $I G F B P-1,-2$ and -5 were downregulated in the glomeruli of diabetic individuals, with $I G F B P-1$ being the most highly 
downregulated gene ( -3.83 fold change, $p=9.6 \times 10^{-4}$ ) (Fig. 1a-f). Transcriptome data from normal human kidney [18] indicated that $I G F B P-1, I G F B P-2$ and $I G F B P-5$ were enriched in glomeruli in comparison with the tubulointerstitium (Fig. 1g-1).

We further analysed IGFBP expression in the Pima DKD cohort [13], where we also found a reduction in glomerular IGFBP-1 in individuals with early-stage disease, compared with living donors (Table 1), which, notably, is unlikely to be purely a consequence of podocyte loss in this cohort. $I G F B P-4$ was also significantly reduced in the glomeruli of this cohort.

Collectively, these results demonstrate a local production and control of IGFBPs in the kidney in type 2 DKD, with a consistent reduction in glomerular $I G F B P-1$ observed in both diabetic cohorts.

PI3K-Akt-Fox01 signalling regulates podocyte IGFBP-1 expression Given that we observed a consistent reduction in glomerular IGFBP-1 expression in both diabetic cohorts, we further explored the mechanisms behind IGFBP-1 regulation. Analysis of single-cell kidney transcriptome data [30] and conditionally immortalised human glomerular cells demonstrated that IGFBP-1 expression and protein secretion were
Table 1 Glomerular $I G F B P-1$ is reduced early in type 2 DKD

\begin{tabular}{llll}
\hline Symbol & \multicolumn{2}{l}{ Early DKD $(n=69)$ vs LD $(n=18)$} \\
\cline { 2 - 4 } & FC & $\log$ FC & Adj. $p$ value \\
\hline IGFBP1 & 0.67 & -0.58 & 0.04 \\
IGFBP2 & 1.31 & 0.39 & 0.00 \\
IGFBP3 & 1.13 & 0.18 & 0.53 \\
IGFBP4 & 0.85 & -0.24 & 0.02 \\
IGFBP5 & 0.87 & -0.21 & 0.09 \\
IGFBP6 & 1.39 & 0.48 & 0.02 \\
\hline
\end{tabular}

Glomerular expression ( $\log _{2}$ mRNA intensity) of IGFBPs in the Pima type 2 diabetes cohort with early $\operatorname{DKD}(n=69)$ vs healthy living donors $(n=18)$

Differential expression was estimated using limma, adjusting for age and sex

$p$ values were adjusted for multiple testing using the BenjaminiHochberg correction

Adj., adjusted; FC, fold change; LD, living donor

most prominent in podocytes, with some signal in glomerular endothelial cells (ESM Fig. 1).

As IGFBP-1 expression is regulated by activity of the transcription factor FoxO1 in other cell types [31], which is in turn
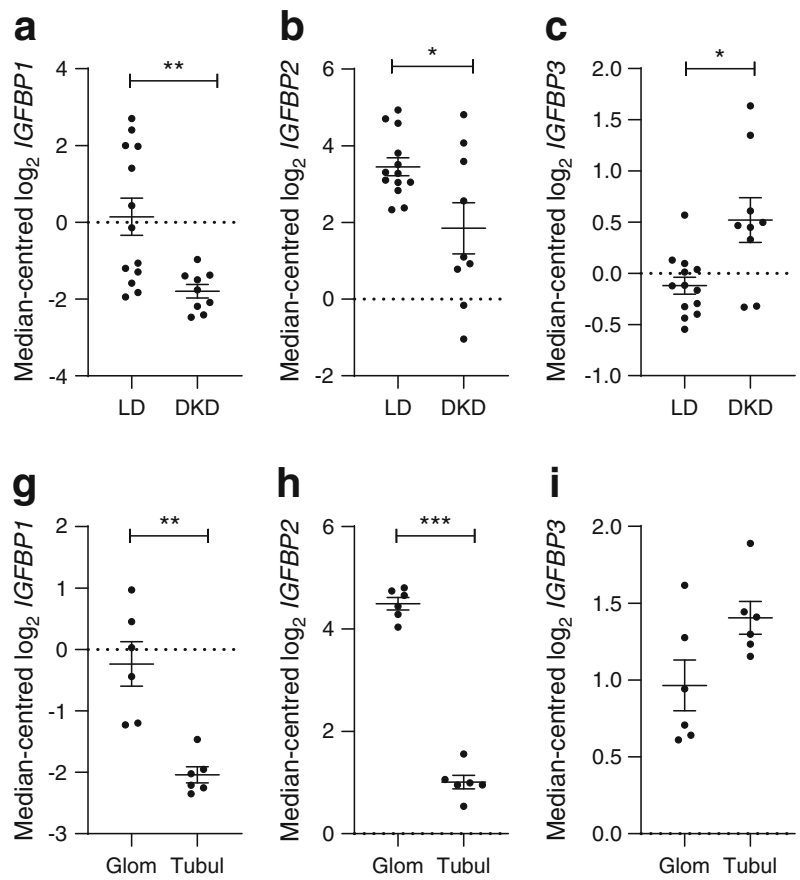

Fig. 1 Changes in glomerular IGFBP expression are observed in type 2 DKD. Data extracted from Nephroseq 'Woroniecka Diabetes Glom' and 'Lindenmeyer Normal Tissue Panel' datasets comparing expression (median-centred $\left.\log _{2}\right)$ of (a) IGFBPI $(q=0.02)$, (b) IGFBP2 $(q=0.18)$, (c) IGFBP3 $(q=0.04)$, (d) IGFBP4 $(q=0.41)$, (e) IGFBP5 $(q=0.04)$ and (f) $\operatorname{IGFBP6}(q=0.09)$, in glomeruli from $\operatorname{DKD}(n=9)$ vs healthy living donors $(n=13), * p<0.05, * * p<0.01$, Welch's $t$ test, $q$ values adjusted
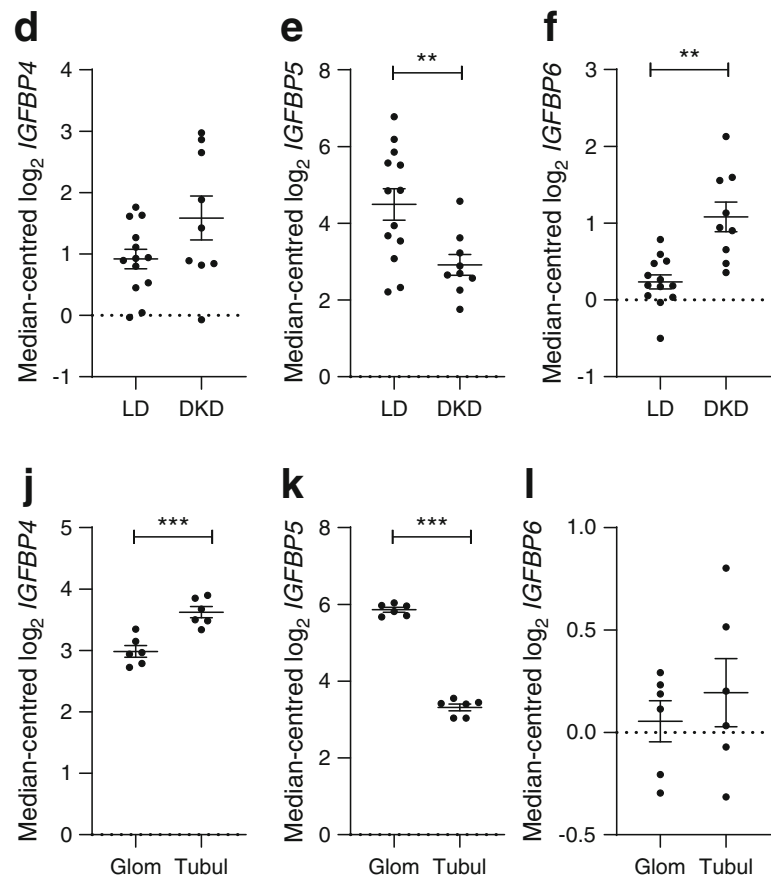

using Benjamini-Hochberg method; and (g) IGFBPI $(q=0.006)$, (h) IGFBP2 $\left(q=1.23 \times 10^{-7}\right)$, (i) IGFBP3 $(q=0.06)$, (j) IGFBP4 $(q=$ $0.001)$, (k) IGFBP5 $\left(q=1.19 \times 10^{-7}\right)$ and (l) IGFBP6 $(q=0.46)$ in glomeruli vs tubulointerstitium, $n=6$ each group, $* * p<0.01$, ***p $p<0.001$, Welch's $t$ test, $q$ values adjusted using Benjamini-Hochberg method. LD, living donor; Glom, glomeruli; Tubul, tubulointerstitium 
regulated by PI3K-Akt signalling [32], we hypothesised that insulin-PI3K-Akt signalling would control FoxO1-driven $I G F B P-1$ expression in glomeruli. To first determine the involvement of FoxO1 in glomerular IGFBP-1 expression, we studied human glomeruli ex vivo alongside glomerular transcriptomics data from diabetic individuals and conditionally immortalised cell lines. In normal human kidney [18] FOXO1 was expressed in both glomerular and tubular regions (ESM Fig. 2). In glomeruli of individuals with type $2 \mathrm{DKD}$ [17], we observed a reduction in FOXO1 expression (Fig. 2a) along with consistent regulation of other reported FoxO1target genes [33] (ESM Fig. 3), indicating that glomerular FoxO1 is negatively regulated in type 2 DKD. Analysis of the Pima DKD cohort [13] indicated that FOXO1 suppression occurred early in DKD progression (Fig. 2b). In ex vivo human glomeruli, the inhibition of FoxO1 (with AS1842856) caused a consistent decrease in IGFBP-1 mRNA (Fig. 2c) and reduced IGFBP-1 protein secretion (Fig. 2d) in each of the three different human glomerular fractions studied. Conditionally immortalised human podocytes also displayed a reduction in IGFBP-1 mRNA expression after $6 \mathrm{~h}$ of FoxO1 inhibition (Fig. 2e), with a corresponding reduction in cellular (Fig. 2f) and secreted (Fig. 2g) IGFBP-1 protein. In contrast, in glomerular endothelial cells, FoxO1
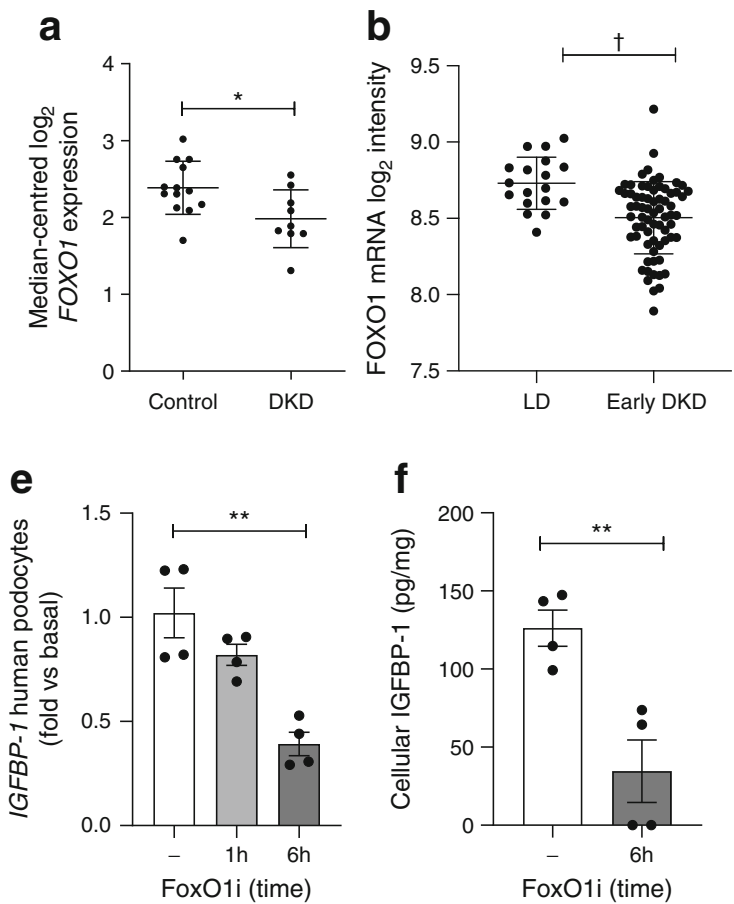

Fig. 2 IGFBP-1 expression is controlled by FoxO1 in human glomeruli and podocytes. (a) Nephroseq: FOXO1 expression in the 'Woroniecka Diabetes Glom' dataset, healthy living donor $(n=13)$ vs DKD $(n=9)$, $* p=0.02$, Welch's $t$ test $(q$ value $=0.10)$. (b) Expression $\left(\log _{2}\right.$ mRNA intensity) of FOXO1 in the Pima type 2 diabetes cohort with early DKD (Early DKD, $n=69$ ) vs living donors (LD, $n=18),{ }^{\dagger} q=0.0003$. (c) qPCR results of $I G F B P-1$ mRNA in ex vivo human glomeruli and (d) IGFBP-1 concentration in glomerular media after FoxO1 inhibition $(50 \mathrm{ng} / \mathrm{ml}$ inhibition had no effect on IGFBP-1 levels (ESM Fig. 4), which may suggest another mechanism of regulation in these cells, such as the mammalian target of rapamycin (mTOR)dependent (FoxO-independent) regulation of IGFBP-1 which has been described by others [34]. Under basal conditions, FoxO1 overexpression had no effect on IGFBP-1 levels in podocytes (ESM Fig. 5), suggesting that it is not solely the expression levels of FoxO1 that are important in regulating gene transcription. Treatment with AS1842856 had no effect on podocyte number over the course of the experiment, indicating there were no toxic effects of this compound (ESM Fig. 6).

Investigating the role of insulin-PI3K-Akt signalling in this pathway, in FoxO1-clover reporter podocytes [21] both FoxO1 inhibition with AS1842856 and insulin stimulation reduced the nuclear levels of FoxO1 (Fig. 3a-c) and increased FoxO1 phosphorylation (Fig. 3d). In the presence of PI3K or Akt inhibitors, the dose-dependent effect of insulin on nuclear FoxO1 exclusion was abolished (Fig. 3e), indicating that insulin-PI3K-Akt signalling inhibits FoxO1 nuclear localisation and activity in human podocytes. Furthermore, insulin stimulation alone reduced cellular IGFBP-1 mRNA (Fig. 3f) in podocytes at $6 \mathrm{~h}$, although we did not detect any significant changes in IGFBP-1 protein by insulin at this time (Fig. 3g, h), which may be due to assay sensitivity or sensitivity of other
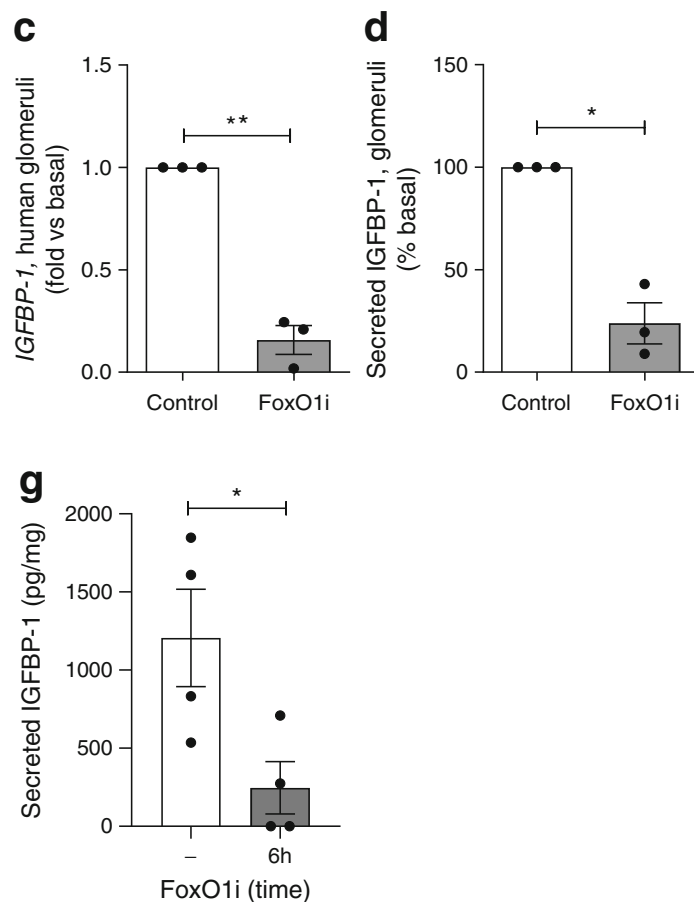

AS1842856 FoxO1 inhibitor) for 10 days, $n=3$ individuals, $* p<0.05$, $* * p<0.01, t$ test. (e) qPCR results of $I G F B P-1$ mRNA expression $(n=4)$, $* * p<0.01$ one-way ANOVA with Tukey's multiple comparison test. (f) IGFBP-1 levels in podocyte lysates normalised to total protein $(n=4)$, $* * p=0.007, t$ test. (g) IGFBP-1 concentration in cell-free podocyte media following $6 \mathrm{~h}$ FoxO1 inhibition (50 ng/ml AS1842856) $(n=4),{ }^{*} p=0.03$, $t$ test, $6 \mathrm{~h}$ vs basal. FoxO1i, FoxO1 inhibitor; qPCR, quantitative PCR 
a

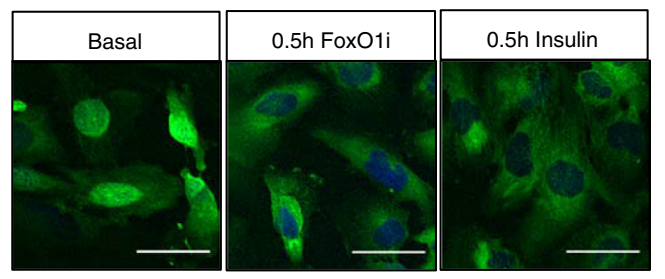

d
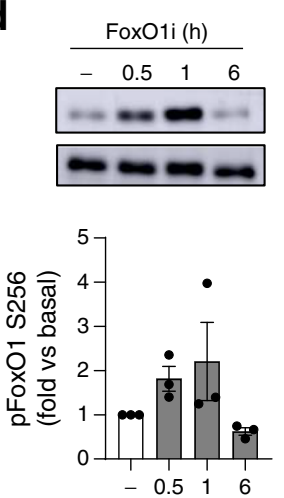

FoxO1i (time, h)
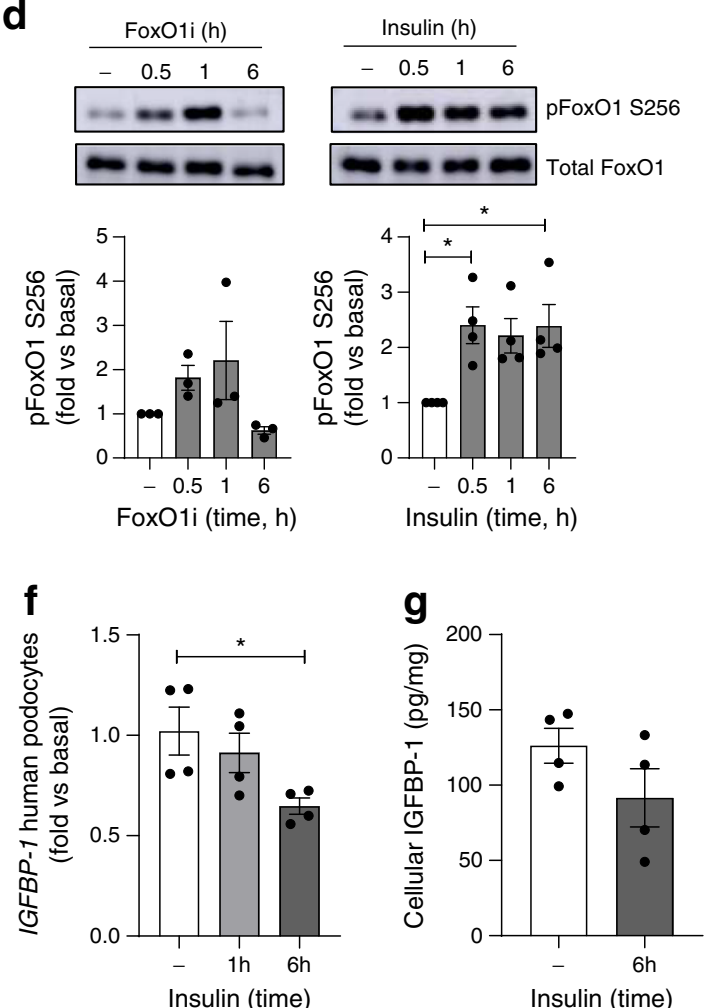

Fig. 3 Insulin-PI3K-Akt signalling regulates FoxO1 activity and IGFBP-1 expression in human podocytes. (a) Representative images (scale bar, $50 \mu \mathrm{m}$ ) of human podocytes stably expressing FoxO1-clover and quantification of nuclear FoxO1-clover levels following (b) FoxO1 inhibition $(50 \mathrm{ng} / \mathrm{ml} \mathrm{AS1842856)}$ or (c) insulin stimulation (100 nmol/l), $n=4$ experiments, $* * p<0.01, * * * p<0.001$, one-way ANOVA with Tukey's multiple comparison test. (d) Representative western blots and matched densitometry demonstrating an increase in phosphorylation of FoxO1 (Ser 256) following insulin stimulation (100 nmol/1), $n=4$, $* p<0.05$ at $0.5 \mathrm{~h}, 1 \mathrm{~h}$ and $6 \mathrm{~h}$, one-way ANOVA with Tukey's multiple comparison test. (e) Quantification of nuclear FoxO1-clover in podocytes

necessary co-factors to insulin stimulation within the time frame. The effects of insulin on IGFBP-1 mRNA expression were also abolished when PI3K was inhibited (ESM Fig. 7).

Thus, increased insulin-PI3K-Akt signalling inhibits FoxO1 transcriptional activity in human podocytes and FoxO1 inhibition leads to suppression of $I G F B P-1$ in podocytes and in human glomeruli.

IGFBPs influence podocyte function Podocyte function at the filtration barrier depends on cell adhesion to the GBM and coordinated regulation of foot process dynamics, largely by
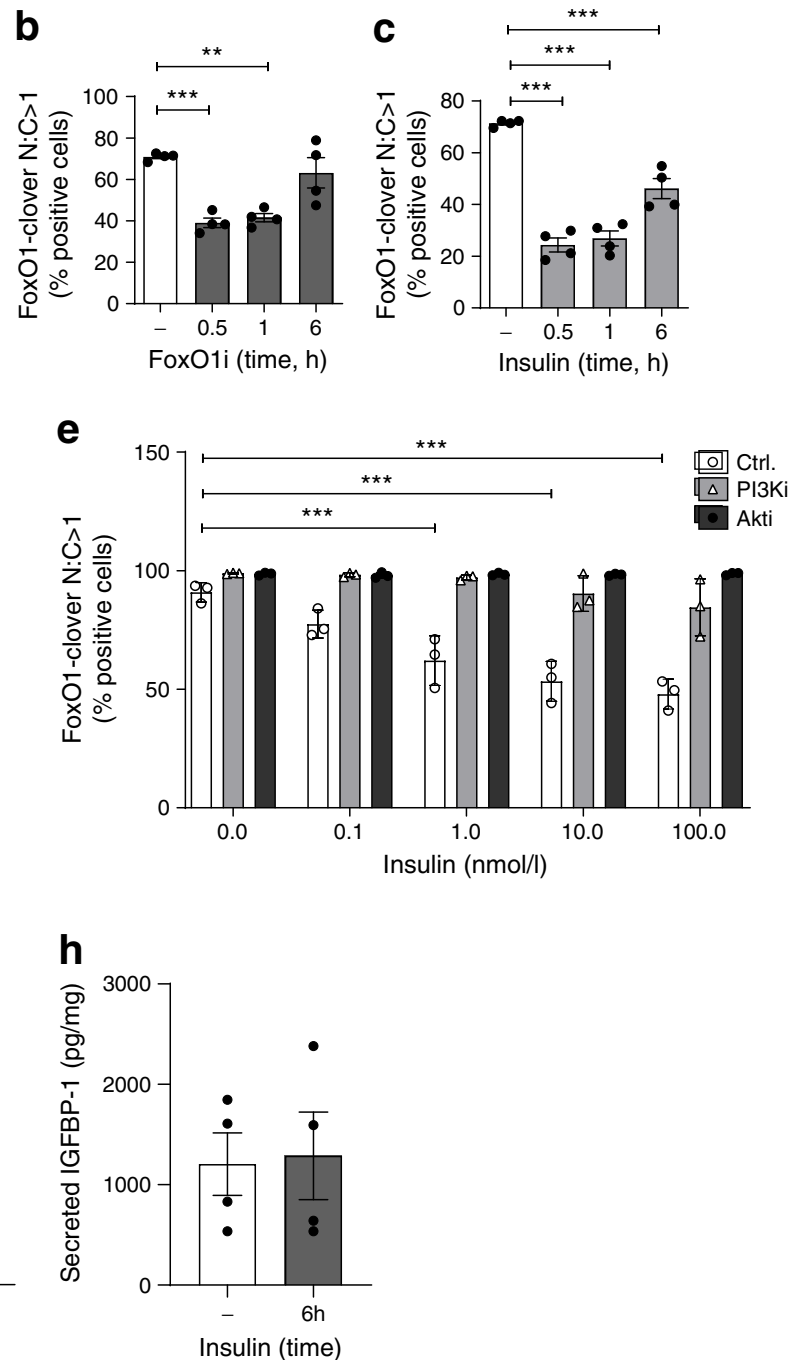

following $30 \mathrm{~min}$ insulin stimulation at the stated doses, with or without additional inhibition of PI3K ( $200 \mathrm{nmol} / \mathrm{l}$ wortmannin) or Akt (200 nmol/ 1 GSK694002), $n=3$, ***p $<0.001$, one-way ANOVA with Tukey's multiple comparison test. (f) qPCR results of IGFBP-1 mRNA following insulin stimulation $(100 \mathrm{nmol} / 1), * p<0.05$, one-way ANOVA with Tukey's multiple comparison test, $n=4$. (g) IGFBP-1 levels (pg) to total protein $(\mathrm{mg})$ in podocyte lysates, $p=0.17$, unpaired $t$ test, and (h) cellfree podocyte media, following insulin stimulation $(100 \mathrm{nmol} / \mathrm{l}), p=0.88$, unpaired $t$ test, $n=4$. Akti, Akt inhibitor; Ctrl., control; FoxO1i, FoxO1 inhibitor; $\mathrm{N}: \mathrm{C}$, ratio of nuclear to cytoplasmic; PI3Ki, PI3K inhibitor

control of the actin cytoskeleton. To investigate whether IGFBP-1 could have effects on these responses we performed ECIS, migration, adhesion and survival assays on conditionally immortalised human podocytes that were starved of serum and IGF and stimulated with IGFBPs.

Measuring electrical resistance across adherent podocytes in vitro, which indicates changes in cell-cell junctions or cellular adhesion [25], we found an increase in electrical resistance following treatment with IGFBP-1, which was significant at $12 \mathrm{~h}$ (Fig. 4a, b). We also observed increased resistance following stimulation with IGFBP-2, IGFBP-3 and IGFBP-4 

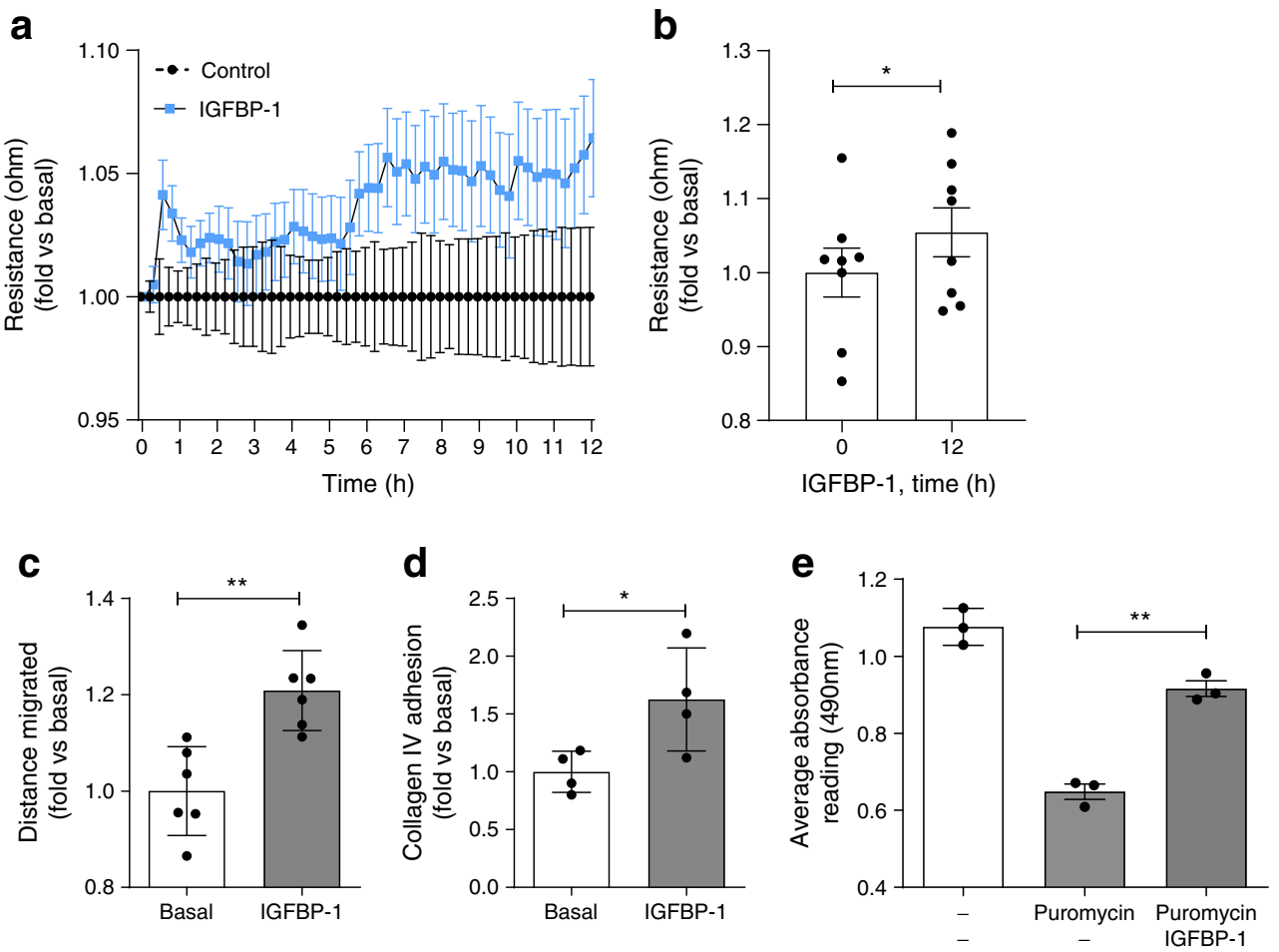

Fig. 4 Stimulation of human podocytes with IGFBP-1 influences cellular function. Human podocytes were starved of serum (including IGF) for 2$4 \mathrm{~h}$ before IGFBP-1 stimulation ( $5 \mathrm{nmol} / \mathrm{l})$. (a) ECIS analysis over $12 \mathrm{~h}$ suggesting increased resistance across adherent human podocytes following IGFBP-1 treatment, normalised to time 0 and vehicle-treated cells, repeated measures one-way ANOVA, $p=0.11$. (b) Bar chart of ECIS analysis, normalised to mean at time 0 , demonstrating an increase in resistance $12 \mathrm{~h}$ post IGFBP-1 stimulation, ${ }^{*} p=0.05$, paired $t$ test, $n=8$. (c) Human podocytes were stimulated with IGFBP-1 and motility was

(ESM Fig. 8), indicating that several IGFBPs may have direct effects on podocyte structure and function.

Studying podocyte motility (as an indication of cytoskeletal signalling and foot process dynamics in vitro), we observed an increase in the migratory response in cells stimulated with IGFBP-1 (Fig. 4c, ESM Fig. 9a), suggesting an increase in cytoskeletal organisation. Using protein-specific adhesion assessed over a period of $12-14 \mathrm{~h}$ and normalised to the mean of the basal (unstimulated) conditions, $* * p=0.002$, unpaired $t$ test, $n=6$. (d) Change in podocyte adhesion to collagen IV following IGFBP-1 stimulation, $n=$ 4 , ${ }^{*} p=0.04$, unpaired $t$ test. (e) Cell viability after exposure of podocytes to puromycin. Human podocytes were treated with puromycin $(50 \mu \mathrm{g} / \mathrm{ml}$, $18 \mathrm{~h}$ ) with or without IGFBP-1 treatment. A significant increase in the number of viable cells was apparent with IGFBP-1 treatment, determined by MTS assays, ${ }^{* *} p<0.01, n=3$, one-way ANOVA with Tukey's multiple comparison test

assays, we also observed an increase in podocyte adhesion to type IV collagen, a major component of the mature GBM [35], following stimulation with IGFBP-1 (Fig. 4d) and IGFBP-4 (ESM Fig. 9b), suggesting that these IGFBPs may improve podocyte attachment to the GBM. Finally, we assessed the direct role of IGFBPs in podocyte survival. Following pre-treatment with puromycin, we found IGFBP-1

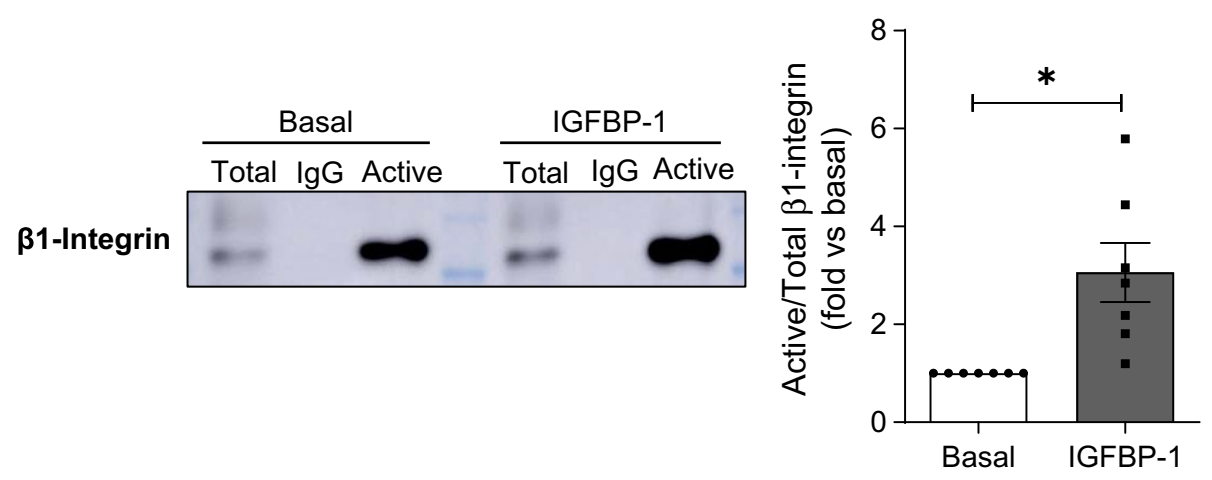

Fig. 5 IGFBP-1 stimulation increases $\beta 1$-integrin activation in human podocytes. Human podocytes were stimulated with IGFBP-1 $(50 \mathrm{ng} / \mathrm{ml}$, $15 \mathrm{~min}$ ) before immunoprecipitation with antibodies specifically recognising conformationally active $\beta 1$-integrin. Representative western blot for $\beta 1$-integrin in both total cell lysates ('Total') and immunoprecipitated fractions ('Active'), and densitometry representing the ratios of Active to Total $\beta 1$-integrin, indicating a higher proportion of Active $\beta 1$-integrin following IGFBP-1 stimulation, $n=7,{ }^{*} p<0.05, t$ test 
a

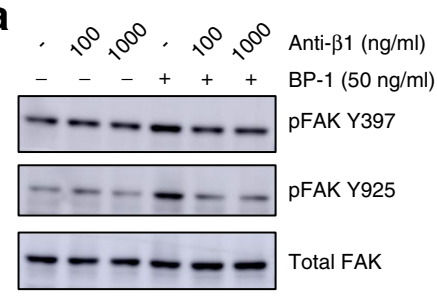

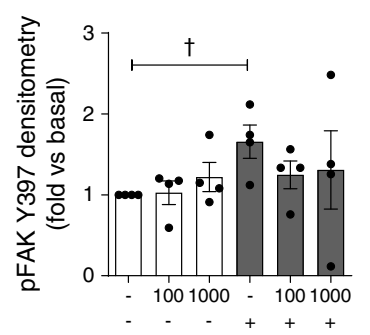

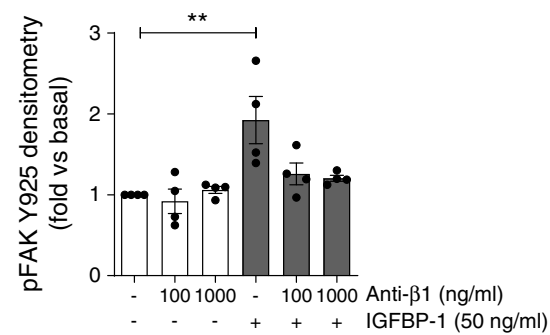

b
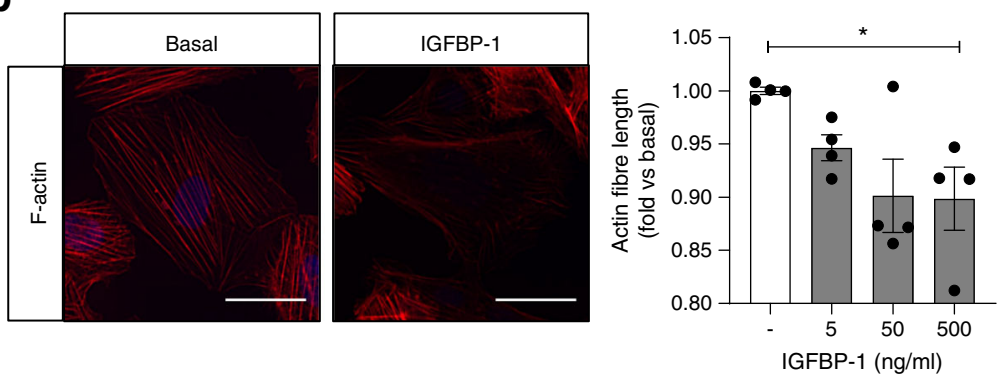

Fig. 6 IGFBP-1 stimulates FA signalling in human podocytes. (a) Representative western blots and densitometry demonstrating the phosphorylation of FAK Y397 and Y925 in human podocytes stimulated with $50 \mathrm{ng} / \mathrm{ml}$ IGFBP-1 for $15 \mathrm{~min}$, with or without pre-treatment with anti$\beta 1$-integrin (Anti- $\beta 1$ ), P5D2 (100 ng/ml or $1000 \mathrm{ng} / \mathrm{ml}, 30 \mathrm{~min}$ ), ${ }^{\dagger} p<0.05, t$ test vs unstimulated, ${ }^{* *} p=0.004$, one-way ANOVA with Tukey's multiple comparison test, $n=4$. (b) Representative images (scale

stimulation significantly increased podocyte viability, measured using MTS assays (Fig. 4e).

Collectively, these observations indicate that IGFBP-1 can influence a variety of podocyte functional responses in vitro. We found IGFBP-2-6 also had effects on podocytes and, as such, further study of other IGFBPs in this context is warranted in the future.

IGFBP-1 regulates $\beta 1$-integrin and focal adhesion signalling in podocytes Given that we found IGFBP-1 influenced multiple processes in human podocytes, we also further explored IGFBP-1-mediated podocyte signalling, focusing on signalling responsible for controlling cell adhesion/migration and the actin cytoskeleton. Interestingly, IGFBP-1 contains functional integrin-binding Arg-Gly-Asp (RGD) domains, and is thought to exert its IGF-independent actions via $\beta 1$-integrin signalling $[8,10]$. As $\beta 1$-integrins are central in controlling cellular adhesion and migration, we investigated whether IGFBP-1 influenced $\beta 1$-integrin activity in podocytes. Using antibodies recognising the active ('extended') conformation of $\beta 1$-integrin, we found a higher proportion of active $\beta 1$ integrin following IGFBP-1 treatment, when compared with basal cells (Fig. 5).

Protein complexes termed focal adhesions (FAs) link integrins to the actin cytoskeleton and act as mediators of integrin signalling. In human podocytes stimulated with IGFBP-1, we found an increase in focal-adhesion kinase (FAK) phosphorylation at both the auto-phosphorylation site,

bar, $50 \mu \mathrm{m}$ ) and automated quantification of mean F-actin fibre length per cell in human podocytes stimulated with IGFBP-1 at the stated concentrations for $60 \min (n=4,3$ replicates per condition, $* p=0.04$, one-way ANOVA with Tukey's multiple comparison test, $500 \mathrm{ng} / \mathrm{ml}$ vs basal). Modest changes in brightness and contrast were uniformly applied to all images for visualisation; unmodified images were used for quantification

Y397, and the Src-regulated phosphorylation site, Y925 (Fig. 6a, ESM Fig. 10a), with no effect on the IGF-IR (phosphorylation at Tyr1135/1136) (ESM Fig. 10b). The pre-treatment of podocytes with the $\beta 1$-integrin blocking antibody, P5D2 [36, 37], reduced IGFBP-1-stimulated FAK phosphorylation (Fig. 6a), although some variability in the response was observed with higher doses of P5D2. We observed no effects on FAK phosphorylation with P5D2 treatment alone at these concentrations. Using automated imaging and analysis, we found that changes in FAK phosphorylation did not occur within the nucleus (ESM Fig. 11) and that this response occurred alongside a small increase in the phosphorylation of paxillin (Y118) at FAs (ESM Fig. 12a, b).

We used automated imaging and analysis to quantify changes in the actin cytoskeleton and found a reduction in length of F-actin fibres after 60 min of IGFBP-1 treatment (Fig. 6b), indicating an increase in F-actin remodelling, although no significant changes in F-actin structures were observed at the shorter time point (ESM Fig. 13). These results suggest that, similar to other cell systems [9, 38], IGFBP-1 can regulate $\beta 1$-integrin/FA/F-actin signalling in human podocytes.

\section{Discussion}

IGFBP-1 is a circulating peptide which is often implicated in metabolic homeostasis. Lower levels of IGFBP-1 in the 
circulation predict type 2 diabetes [39], the metabolic syndrome [40] and the risk of developing cardiovascular disease [41]. Furthermore, disruptions to IGFBP-1 have also been associated with diabetic nephropathy [42], with polymorphisms in IGFBP-1 associated with kidney disease in type 2 diabetes [7].

In the present study, we investigated the local control and actions of IGFBPs in the glomerulus and found that glomerular IGFBP-1 was significantly reduced in individuals with type $2 \mathrm{DKD}$, where it was expressed and secreted by podocytes, demonstrating local glomerular control of IGFBP-1. Furthermore, we found IGFBP-1 had direct, IGFindependent effects on podocytes, by increasing podocyte adhesion and migration in vitro as well as increasing electrical resistance across the adhesive cell layer, responses that relate to control of the actin cytoskeleton and are important for cell function at the filtration barrier. It also had pro-survival effects on puromycin-treated podocytes.

Mechanistically, we found that glomerular IGFBP-1 expression was controlled by FoxO1 activity, which was in turn regulated by insulin-PI3K-Akt signalling in podocytes, consistent with findings in other tissues including the liver, the major source of circulating IGFBP-1 [32]. Indeed, reductions in circulating IGFBP-1 are often attributed to the inhibitory effects of hyperinsulinaemia on hepatic IGFBP-1 expression, prior to the development of hepatic insulin resistance. As podocytes are insulin-sensitive cells, with both insulin resistance and excessive signalling activity being detrimental to cell function $[26,27,43]$, it is plausible that the reduced glomerular IGFBP-1 observed early in type 2 DKD could also be a consequence of excessive insulin signalling, prior to the development of podocyte insulin resistance, in this regard mirroring the regulation of IGFBP- 1 expression in the liver early in diabetes.

Our study also supports the notion that reduced FoxO1 expression and activity occurs in DKD [44], as we found both a reduction in glomerular FOXO1 in two diabetic cohorts and consistent regulation of FoxO1target genes. In contrast to these findings, an increase in $I g f b p-1$ has previously been reported in the kidney and liver of $d b / d b$ mice [45], with an apparent decrease in phosphorylated FoxO1. These contradictory results may in part be explained if insulin resistance was apparent in the kidneys of the $d b / d b$ mice at the time point studied, which would plausibly increase FoxO1 activity, similar to the increased $I g f b p-1$ expression observed in rodent models of type 1 diabetes [46] which occurs due to an absence of insulin and insulin signalling. Notably, others have previously shown that FoxO1 overexpression is beneficial in DKD, at least in part by the protection of podocytes against epithelial-mesenchymal transition [47]; based on our findings it would be interesting to determine the role of IGFBP-1 in this pathway.
Further exploring the IGF-independent IGFBP-1 signalling responses in podocytes, we found an increase in active $\beta 1$ integrin following IGFBP-1 treatment. This is in line with other cell systems, where the effects of IGFBP-1 on cellular adhesion, motility and survival have been attributed to the modulation of $\beta 1$-integrin/FAK $[9,10]$. In podocytes, the regulation of $\beta 1$-integrin is particularly important, as highlighted in podocyte-specific $\beta 1$-integrin-knockout mice, which develop a severe proteinuric renal disease from birth $[48,49]$, and in patients where stabilising $\beta 1$-integrin activation protects against proteinuria $[50,51]$, implicating an important, IGF-independent role of IGFBP-1 in podocyte health via its ability to modulate $\beta 1$-integrin activity. This also indicates the mechanism by which IGFBP-1 may influence podocyte motility, adhesion and electrical resistance.

Downstream of $\beta 1$-integrin, we found that IGFBP-1 stimulated the phosphorylation of FAK, a central component of FAs involved in cell migration, adhesion, spreading and survival [52], which was blocked in the presence an anti- $\beta 1$ integrin antibody known to suppress $\beta 1$-integrin function [36, 37]. Furthermore, we observed a reduction in F-actin stress fibres after IGFBP-1 treatment, supporting a role of IGFBP-1 in regulating FA signalling and the podocyte cytoskeleton. Importantly, these responses were demonstrated in the absence of IGF-I and occurred with no change in activation of IGF-IR.

As podocyte function at the filtration barrier depends on adhesion to the GBM, with detachment from the basement membrane being a major driving factor in albuminuria [53], and changes in podocyte motility and cytoskeletal organisation often associated with changes in foot process dynamics in vivo [54], the ability of IGFBP-1 to control these responses has important implications for podocyte function. Indeed, increased FAK activity has been associated with collagen adhesion [55] and pro-survival signalling, relating to F-actin modulation [56], indicating there are beneficial roles of FAK activity in podocyte biology, which mirrors our findings. However, there is also evidence that increased FAK activity occurs in glomerular disease, with podocyte-specific knockdown of FAK protecting against foot process effacement in vivo, corresponding with increased stress fibre formation and reduced cell migration in vitro [57]. These differences likely reflect the complexity of FA signalling and the necessity for controlled regulation of these signalling pathways. Whether the activation of FAK is ultimately beneficial or detrimental also likely depends on context and localisation within cells. Additionally, it is increasingly acknowledged that $2 \mathrm{D}$ in vitro cell culture conditions have an impact on these pathways. As such, studies on the dynamic regulation of these signalling pathways by IGFBP-1 in vivo will be beneficial in future.

Others have also previously found that transgenic mice overexpressing human IGFBP-1 from the liver developed 
glomerular disease [58], suggesting persistent increases in systemic IGFBP-1 may be detrimental. Although the mechanisms of this glomerular phenotype were not defined, it is possible that this was a consequence of reduced IGF-I bioavailability during kidney development. There is also evidence that IGFBP-1 may increase in nephrotic syndrome [5, 6]. Further work is clearly required to determine whether increasing (or maintaining) glomerular IGFBP-1 expression is beneficial to podocyte function early in type 2 DKD in addition to defining the IGFdependent effects of IGFBP-1 in renal cells.

Although the effects of increasing IGFBP-1 in podocytes in type $2 \mathrm{DKD}$ in vivo are to be determined, protective effects of IGFBP-1 in diabetes and insulin resistance have been shown in models of cardiovascular disease, where it can improve blood pressure, NO production, atherosclerosis and vascular repair via its integrin-binding RGD domain [23, 38, 59]. Interestingly, increased circulating IGFBP-1 has also been shown to improve insulin sensitivity of pancreatic beta cells and skeletal muscle, again by increased RGD signalling [23]. It is therefore also possible that a loss of glomerular IGFBP-1 expression could contribute towards podocyte insulin resistance in type 2 diabetes. Given the importance of regulated insulin signalling in podocytes [26, 43, 60], it would also be interesting to determine whether maintaining IGFBP-1 (RGD) signalling has similar beneficial effects on podocyte insulin sensitivity in this context.

In summary, this study demonstrates that IGFBP-1 can have direct, IGF-independent effects on podocyte function, modulating $\beta 1$-integrin-FA pathways. We observed a significant reduction in glomerular IGFBP-1 early in type $2 \mathrm{DKD}$, where it is expressed by podocytes and regulated by the transcription factor FoxO1. We further confirm the regulation of FoxO1 activity by insulin-PI3K-Akt signalling in podocytes and provide additional evidence that FoxO1 is suppressed in the glomerulus in type $2 \mathrm{DKD}$. Thus, increased insulin signalling in early diabetes, prior to the development of glomerular insulin resistance, may suppress FoxO1 activity and IGFBP-1 expression in the glomerulus and associated signalling. Strategies to maintain IGFBP-1 levels in diabetes may support podocyte function and be therapeutically beneficial.

Supplementary Information The online version contains peer-reviewed but unedited supplementary material available at https://doi.org/10.1007/ s00125-021-05427-1.

Funding This study was supported by funding from the MRC, which funded RJMC with a Senior Research Fellowship (MR/K010492/1), and Kidney Research UK who supported ACL with a project grant awarded to RJMC (RP26/2014). ACL and RJMC are currently supported by funding from the Horizon2020-IMI Biomarker Enterprise to Attack Diabetic Kidney Disease (BEAt-DKD) consortium. The Society for Endocrinology provided support for this project to ACL and HS-C with an undergraduate summer studentship. This work was partially supported by the National Institute of Diabetes and Digestive and Kidney Diseases (P30DK081943). RGN was supported by the Intramural Research Program of the National Institute of Diabetes and Digestive and Kidney Diseases. RR was funded by grants JF-S/RP/2015/4 and Paed_RP_006_ 20170929 from Kidney Research UK.

Data availability All data generated or analysed during this study are included in this published article (and its supplementary information files) or are available from the corresponding author upon reasonable request.

Authors' relationships and activities The authors declare that there are no relationships or activities that might bias, or be perceived to bias, their work.

Contribution statement ACL, LJH, HS-C, RJPP, EM, JAH, RR, LG and JA performed experiments. LJH performed ECIS, motility and adhesion assays. HS-C and RR performed immunoprecipitation experiments. $\mathrm{BH}$ and TR isolated human glomeruli for ex vivo studies. JMPH, CMP, CAM and GIW advised on the design of in vitro experiments and the interpretation of the results. VN, RGN, WJ and MK conducted the Pima type 2 diabetic cohort study and performed expression analysis. RJMC, ACL and LJH conceived the project. ACL wrote the manuscript. RJMC and ACL secured the funding for this project. All authors intellectually commented on and edited the manuscript and approved the final version. RJMC is the guarantor of this work.

Open Access This article is licensed under a Creative Commons Attribution 4.0 International License, which permits use, sharing, adaptation, distribution and reproduction in any medium or format, as long as you give appropriate credit to the original author(s) and the source, provide a link to the Creative Commons licence, and indicate if changes were made. The images or other third party material in this article are included in the article's Creative Commons licence, unless indicated otherwise in a credit line to the material. If material is not included in the article's Creative Commons licence and your intended use is not permitted by statutory regulation or exceeds the permitted use, you will need to obtain permission directly from the copyright holder. To view a copy of this licence, visit http://creativecommons.org/licenses/by/4.0/.

\section{References}

1. Matsushita K, van der Velde M, Astor BC et al (2010) Association of estimated glomerular filtration rate and albuminuria with allcause and cardiovascular mortality in general population cohorts: a collaborative meta-analysis. Lancet (London, England) 375(9731):2073-2081. https://doi.org/10.1016/s0140-6736(10) 60674-5

2. Pagtalunan ME, Miller PL, Jumping-Eagle S et al (1997) Podocyte loss and progressive glomerular injury in type II diabetes. J Clin Invest 99(2):342-348. https://doi.org/10.1172/jci119163

3. Toyoda M, Najafian B, Kim Y, Caramori ML, Mauer M (2007) Podocyte detachment and reduced glomerular capillary endothelial fenestration in human type 1 diabetic nephropathy. Diabetes 56(8): 2155-2160. https://doi.org/10.2337/db07-0019

4. Vasylyeva TL, Ferry RJ Jr (2007) Novel roles of the IGF-IGFBP axis in etiopathophysiology of diabetic nephropathy. Diabetes Res Clin Pract 76(2):177-186. https://doi.org/10.1016/j.diabres.2006. 09.012

5. Worthmann K, Peters I, Kümpers P et al (2010) Urinary excretion of IGFBP-1 and -3 correlates with disease activity and differentiates focal segmental glomerulosclerosis and minimal change disease. 
Growth Factors 28(2):129-138. https://doi.org/10.3109/ 08977190903512594

6. Peters I, Tossidou I, Achenbach J et al (2006) IGF-binding protein3 modulates TGF-beta/BMP-signaling in glomerular podocytes. J Am Soc Nephrol 17(6):1644-1656. https://doi.org/10.1681/asn. 2005111209

7. Stephens RH, McElduff P, Heald AH et al (2005) Polymorphisms in IGF-binding protein 1 are associated with impaired renal function in type 2 diabetes. Diabetes 54(12):3547-3553. https://doi.org/ 10.2337/diabetes.54.12.3547

8. Firth SM, Baxter RC (2002) Cellular actions of the insulin-like growth factor binding proteins. Endocr Rev 23(6):824-854. https://doi.org/10.1210/er.2001-0033

9. Ammoun S, Schmid MC, Zhou L et al (2012) Insulin-like growth factor-binding protein-1 (IGFBP-1) regulates human schwannoma proliferation, adhesion and survival. Oncogene 31(13):1710-1722. https://doi.org/10.1038/onc.2011.357

10. Jones JI, Gockerman A, Busby WH Jr, Wright G, Clemmons DR (1993) Insulin-like growth factor binding protein 1 stimulates cell migration and binds to the alpha 5 beta 1 integrin by means of its Arg-Gly-Asp sequence. Proc Natl Acad Sci U S A 90(22):1055310557. https://doi.org/10.1073/pnas.90.22.10553

11. Hale LJ, Welsh GI, Perks CM et al (2013) Insulin-like growth factor-II is produced by, signals to and is an important survival factor for the mature podocyte in man and mouse. J Pathol 230(1):95-106. https://doi.org/10.1002/path.4165

12. Ising $\mathrm{C}$, Koehler $\mathrm{S}$, Brahler $\mathrm{S}$ et al (2015) Inhibition of insulin/IGF1 receptor signaling protects from mitochondria-mediated kidney failure. EMBO Mol Med 7(3):275-287. https://doi.org/10.15252/ emmm.201404916

13. Weil EJ, Fufaa G, Jones LI et al (2013) Effect of losartan on prevention and progression of early diabetic nephropathy in American Indians with type 2 diabetes. Diabetes 62(9):3224-3231. https:// doi.org/10.2337/db12-1512

14. Schmid H, Boucherot A, Yasuda Y et al (2006) Modular activation of nuclear factor-kappaB transcriptional programs in human diabetic nephropathy. Diabetes 55(11):2993-3003. https://doi.org/10. 2337/db06-0477

15. Martini S, Nair V, Keller BJ et al (2014) Integrative biology identifies shared transcriptional networks in CKD. J Am Soc Nephrol 25(11):2559-2572. https://doi.org/10.1681/asn.2013080906

16. Nair V, Komorowsky CV, Weil EJ et al (2018) A molecular morphometric approach to diabetic kidney disease can link structure to function and outcome. Kidney Int 93(2):439-449. https:// doi.org/10.1016/j.kint.2017.08.013

17. Woroniecka KI, Park AS, Mohtat D, Thomas DB, Pullman JM, Susztak K (2011) Transcriptome analysis of human diabetic kidney disease. Diabetes 60(9):2354-2369. https://doi.org/10.2337/db101181

18. Lindenmeyer MT, Eichinger F, Sen K et al (2010) Systematic analysis of a novel human renal glomerulus-enriched gene expression dataset. PLoS One 5(7):e11545. https://doi.org/10.1371/journal. pone.0011545

19. Saleem MA, O'Hare MJ, Reiser J et al (2002) A conditionally immortalized human podocyte cell line demonstrating nephrin and podocin expression. J Am Soc Nephrol 13(3):630-638

20. Satchell SC, Tasman CH, Singh A et al (2006) Conditionally immortalized human glomerular endothelial cells expressing fenestrations in response to VEGF. Kidney Int 69(9):1633-1640. https:// doi.org/10.1038/sj.ki.5000277

21. Pope RJ, Garner KL, Voliotis M et al (2020) An information theoretic approach to insulin sensing by human kidney podocytes. Mol Cell Endocrinol 518:110976. https://doi.org/10.1016/j.mce.2020. 110976

22. Yu H, Mistry J, Nicar MJ et al (1999) Insulin-like growth factors (IGF-I, free IGF-I and IGF-II) and insulin-like growth factor binding proteins (IGFBP-2, IGFBP-3, IGFBP-6, and ALS) in blood circulation. J Clin Lab Anal 13(4):166-172. https://doi.org/10. 1002/(SICI)1098-2825(1999)13:4<166::AID-JCLA5>3.0.CO;2-X

23. Haywood NJ, Cordell PA, Tang KY et al (2017) Insulin-like growth factor binding protein 1 could improve glucose regulation and insulin sensitivity through its RGD domain. Diabetes 66(2): 287-299. https://doi.org/10.2337/db16-0997

24. Vollenbroker B, George B, Wolfgart M, Saleem MA, Pavenstadt H, Weide T (2009) mTOR regulates expression of slit diaphragm proteins and cytoskeleton structure in podocytes. Am J Physiol Renal Physiol 296(2):F418-F426. https://doi.org/10.1152/ ajprenal.90319.2008

25. Satchell SC, Buchatska O, Khan SB et al (2007) Interferon-beta reduces proteinuria in experimental glomerulonephritis. J Am Soc Nephrol 18(11):2875-2884. https://doi.org/10.1681/ASN. 2006101104

26. Lay AC, Hurcombe JA, Betin VMS et al (2017) Prolonged exposure of mouse and human podocytes to insulin induces insulin resistance through lysosomal and proteasomal degradation of the insulin receptor. Diabetologia 60(11):2299-2311. https://doi.org/ 10.1007/s00125-017-4394-0

27. Garner KL, Betin VMS, Pinto V et al (2018) Enhanced insulin receptor, but not $\mathrm{PI} 3 \mathrm{~K}$, signalling protects podocytes from ER stress. Sci Rep 8(1):3902. https://doi.org/10.1038/s41598-01822233-9

28. Ritchie ME, Phipson B, Wu D et al (2015) limma powers differential expression analyses for RNA-sequencing and microarray studies. Nucleic Acids Res 43(7):e47. https://doi.org/10.1093/nar/ gkv007

29. Phipson B, Lee S, Majewski IJ, Alexander WS, Smyth GK (2016) Robust hyperparameter estimation protects against hypervariable genes and improves power to detect differential expression. Ann Appl Stat 10(2):946-963. https://doi.org/10.1214/16-aoas920

30. Menon R, Otto EA, Hoover P et al (2020) Single cell transcriptomics identifies focal segmental glomerulosclerosis remission endothelial biomarker. JCI Insight 5(6):e133267. https://doi.org/10. 1172/jci.insight. 133267

31. Durham SK, Suwanichkul A, Scheimann AO et al (1999) FKHR binds the insulin response element in the insulin-like growth factor binding protein-1 promoter. Endocrinology 140(7):3140-3146. https://doi.org/10.1210/endo.140.7.6856

32. Van Der Heide LP, Hoekman MF, Smidt MP (2004) The ins and outs of FoxO shuttling: mechanisms of FoxO translocation and transcriptional regulation. Biochem J 380(Pt 2):297-309. https:// doi.org/10.1042/bj20040167

33. Batista TM, Garcia-Martin R, Cai W et al (2019) Multi-dimensional transcriptional remodeling by physiological insulin in vivo. Cell Rep 26(12):3429-3443.e3423. https://doi.org/10.1016/j.celrep. 2019.02.081

34. Patel S, Lochhead PA, Rena G et al (2002) Insulin regulation of insulin-like growth factor-binding protein-1 gene expression is dependent on the mammalian target of rapamycin, but independent of ribosomal S6 kinase activity. J Biol Chem 277(12):9889-9895. https://doi.org/10.1074/jbc.M109870200

35. Lennon R, Byron A, Humphries JD et al (2014) Global analysis reveals the complexity of the human glomerular extracellular matrix. J Am Soc Nephrol 25(5):939-951. https://doi.org/10. 1681/asn.2013030233

36. Dittel BN, McCarthy JB, Wayner EA, LeBien TW (1993) Regulation of human B-cell precursor adhesion to bone marrow stromal cells by cytokines that exert opposing effects on the expression of vascular cell adhesion molecule-1 (VCAM-1). Blood 81(9): 2272-2282. https://doi.org/10.1182/blood.V81.9.2272.2272

37. Yokosaki Y, Palmer EL, Prieto AL et al (1994) The integrin alpha 9 beta 1 mediates cell attachment to a non-RGD site in the third 
fibronectin type III repeat of tenascin. J Biol Chem 269(43):2669126696. https://doi.org/10.1016/S0021-9258(18)47074-3

38. Aziz A, Haywood NJ, Cordell PA et al (2018) Insulinlike growth factor-binding protein-1 improves vascular endothelial repair in male mice in the setting of insulin resistance. Endocrinology 159(2):696-709. https://doi.org/10.1210/en.2017-00572

39. Lewitt MS, Hilding A, Ostenson CG, Efendic S, Brismar K, Hall K (2008) Insulin-like growth factor-binding protein-1 in the prediction and development of type 2 diabetes in middle-aged Swedish men. Diabetologia 51(7):1135-1145. https://doi.org/10.1007/ s00125-008-1016-x

40. Maddux BA, Chan A, De Filippis EA, Mandarino LJ, Goldfine ID (2006) IGF-binding protein-1 levels are related to insulin-mediated glucose disposal and are a potential serum marker of insulin resistance. Diabetes Care 29(7):1535-1537. https://doi.org/10.2337/ dc05-1367

41. Heald AH, Cruickshank JK, Riste LK et al (2001) Close relation of fasting insulin-like growth factor binding protein-1 (IGFBP-1) with glucose tolerance and cardiovascular risk in two populations. Diabetologia 44(3):333-339. https://doi.org/10.1007/ s001250051623

42. Gu T, Falhammar H, Gu HF, Brismar K (2014) Epigenetic analyses of the insulin-like growth factor binding protein 1 gene in type 1 diabetes and diabetic nephropathy. Clin Epigenetics 6(1):10. https:// doi.org/10.1186/1868-7083-6-10

43. Lay AC, Coward RJM (2018) The evolving importance of insulin signaling in podocyte health and disease. Front Endocrinol (Lausanne) 9(693). https://doi.org/10.3389/fendo.2018.00693

44. Fiorentino L, Cavalera M, Menini S et al (2013) Loss of TIMP3 underlies diabetic nephropathy via FoxO1/STAT1 interplay. EMBO Mol Med 5(3):441-455. https://doi.org/10.1002/emmm. 201201475

45. Segev Y, Eshet R, Yakir O, Haim N, Phillip M, Landau D (2007) Systemic and renal growth hormone-IGF1 axis involvement in a mouse model of type 2 diabetes. Diabetologia 50(6):1327-1334. https://doi.org/10.1007/s00125-007-0663-7

46. Segev Y, Landau D, Marbach M, Shehadeh N, Flyvbjerg A, Phillip M (1997) Renal hypertrophy in hyperglycemic non-obese diabetic mice is associated with persistent renal accumulation of insulin-like growth factor I. J Am Soc Nephrol 8(3):436-444

47. Du M, Wang Q, Li W et al (2016) Overexpression of FOXO1 ameliorates the podocyte epithelial-mesenchymal transition induced by high glucose in vitro and in vivo. Biochem Biophys Res Commun 471(4):416-422. https://doi.org/10.1016/j.bbrc. 2016.02.066

48. Pozzi A, Jarad G, Moeckel GW et al (2008) Beta1 integrin expression by podocytes is required to maintain glomerular structural integrity. Dev Biol 316(2):288-301. https://doi.org/10.1016/j. ydbio.2008.01.022

49. Kanasaki K, Kanda Y, Palmsten K et al (2008) Integrin beta1mediated matrix assembly and signaling are critical for the normal development and function of the kidney glomerulus. Dev Biol 313(2):584-593. https://doi.org/10.1016/j.ydbio.2007.10.047

50. Greka A, Weins A, Mundel P (2014) Abatacept in B7-1-positive proteinuric kidney disease. N Engl J Med 370(13):1263-1266. https://doi.org/10.1056/NEJMc1400502

51. Yu C-C, Fornoni A, Weins A et al (2013) Abatacept in B7-1positive proteinuric kidney disease. 369(25):2416-2423. https:// doi.org/10.1056/NEJMoa1304572

52. Mitra SK, Hanson DA, Schlaepfer DD (2005) Focal adhesion kinase: in command and control of cell motility. Nat Rev Mol Cell Biol 6(1):56-68. https://doi.org/10.1038/nrm1549

53. Lennon R, Randles MJ, Humphries MJ (2014) The importance of podocyte adhesion for a healthy glomerulus. Front Endocrinol (Lausanne) 5:160. https://doi.org/10.3389/fendo.2014.00160

54. Welsh GI, Saleem MA (2011) The podocyte cytoskeleton-key to a functioning glomerulus in health and disease. Nat Rev Nephrol 8(1):14-21. https://doi.org/10.1038/nrneph.2011.151

55. Watanabe K, Watanabe K, Watanabe Y et al (2018) Human soluble phospholipase A2 receptor is an inhibitor of the integrin-mediated cell migratory response to collagen-I. Am J Physiol Cell Physiol 315(3):C398-c408. https://doi.org/10.1152/ajpcell.00239.2017

56. Bijian K, Takano T, Papillon J et al (2005) Actin cytoskeleton regulates extracellular matrix-dependent survival signals in glomerular epithelial cells. Am J Physiol Renal Physiol 289(6):F1313F1323. https://doi.org/10.1152/ajprenal.00106.2005

57. Ma H, Togawa A, Soda $\mathrm{K}$ et al (2010) Inhibition of podocyte FAK protects against proteinuria and foot process effacement. J Am Soc Nephrol 21(7):1145-1156. https://doi.org/10.1681/asn. 2009090991

58. Doublier S, Seurin D, Fouqueray B et al (2000) Glomerulosclerosis in mice transgenic for human insulin-like growth factor-binding protein-1. Kidney Int 57(6):2299-2307. https://doi.org/10.1046/j. 1523-1755.2000.00090.x

59. Rajwani A, Ezzat V, Smith J et al (2012) Increasing circulating IGFBP1 levels improves insulin sensitivity, promotes nitric oxide production, lowers blood pressure, and protects against atherosclerosis. Diabetes 61(4):915-924. https://doi.org/10.2337/db11-0963

60. Welsh GI, Hale LJ, Eremina V et al (2010) Insulin signaling to the glomerular podocyte is critical for normal kidney function. Cell Metab 12(4):329-340. https://doi.org/10.1016/j.cmet.2010.08.015

Publisher's note Springer Nature remains neutral with regard to jurisdictional claims in published maps and institutional affiliations. 